\title{
Are vegetation-specific model parameters required for estimating gross primary production?
}

\section{Journal Article}

\section{Author(s):}

Yuan, Wenping; Liu, S.; Cai, W.; Dong, W.; Chen, J.; Arain, Altaf; Blanken, Peter D.; Cescatti, Alessandro; Wohlfahrt, Georg; Georgiadis, Teodoro; Genesio, Lorenzo; Gianelle, Damiano; Grelle, A.; Kiely, Ger; Knohl, Alexander; Liu, D.; Marek, M.; Merbold, Lutz; Montagnani, Leonardo; Panferov, Oleg; Peltoniemi, Mikko; Rambal, Serge; Raschi, Antonio; Varlagin, Andrej; Xia, J.

\section{Publication date:}

2013

Permanent link:

https://doi.org/10.3929/ethz-b-000077871

Rights / license:

Creative Commons Attribution 3.0 Unported

Originally published in:

Geoscientific Model Development 6, https://doi.org/10.5194/gmdd-6-5475-2013 


\section{Are vegetation-specific model parameters required for estimating gross primary production?}

W. Yuan ${ }^{1,2}$, S. Liu $^{3}$, W. Cai ${ }^{1}$, W. Dong ${ }^{1}$, J. Chen ${ }^{4,5}$, A. Arain ${ }^{6}$, P. D. Blanken ${ }^{7}$, A. Cescatti ${ }^{8}$, G. Wohlfahrt ${ }^{9}$, T. Georgiadis ${ }^{10}$, L. Genesio ${ }^{11}$, D. Gianelle ${ }^{12}$, A. Grelle ${ }^{13}$, G. Kiely ${ }^{14}$, A. Knohl' ${ }^{15}$, D. Liu ${ }^{1}$, M. Marek ${ }^{16}$, L. Merbold ${ }^{17}$, L. Montagnani ${ }^{18}$, O. Panferov ${ }^{15}$, M. Peltoniemi ${ }^{19}$, S. Rambal ${ }^{20}$, A. Raschi ${ }^{11}$, A. Varlagin ${ }^{21}$, and J. Xia ${ }^{1}$

${ }^{1}$ State Key Laboratory of Earth Surface Processes and Resource Ecology, Beijing Normal University, Beijing 100875, China

${ }^{2}$ State Key Laboratory of Cryospheric Sciences, Cold and Arid Regions Environmental and Engineering Research Institute, The Chinese Academy of Sciences, Lanzhou, Gansu 730000, China

${ }^{3}$ State Engineering Laboratory of Southern Forestry Applied Ecology and Technology, Central South University of Forestry and Technology, Changsha, Hunan 410004, China ${ }^{4}$ International Center for Ecology, Meteorology and Environment, School of Applied Meteorology, Nanjing University of Information Science and Technology, Nanjing 210044, China

${ }^{5}$ Department of Environmental Sciences, University of Toledo, Toledo, $\mathrm{OH} 43606$, USA

Remote sensing of

gross primary

production

W. Yuan et al
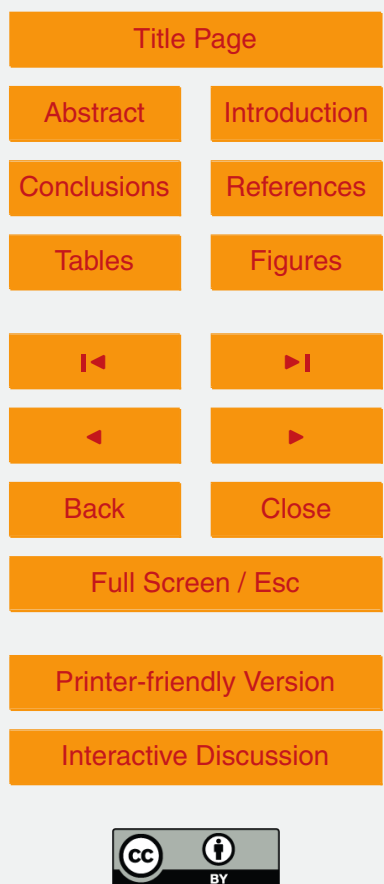
${ }^{6}$ School of Geography and Earth Sciences, McMaster University, Hamilton, Ontario, Canada

${ }^{7}$ Department of Geography, University of Colorado at Boulder, Boulder, CO 80309, USA

${ }^{8}$ European Commission, Joint Research Center, Institute for Environment and Sustainability, Ispra, Italy

${ }^{9}$ Institute of Ecology, University of Innsbruck, Sternwartestrasse 15, 6020 Innsbruck, Austria

${ }^{10}$ IBIMET-CNR, Institute of Biometeorology, National Research Council, Via Gobetti, 101,

Bologna, 40129, Italy

${ }^{11}$ IBIMET-CNR, Institute of Biometeorology, National Research Council, Via G. Caproni, 8, Firenze, 50145, Italy

${ }^{12}$ Sustainable Agro-ecosystems and Bioresources Department, Research and Innovation

Centre, Fondazione E. Mach, San Michele all'Adige, Italy

${ }^{13}$ Department of Ecology, Swedish University of Agricultural Sciences, 750 07, Uppsala, Sweden

${ }^{14}$ Civil \& Environmental Engineering Dept and Environmental Research Institute, University College Cork, Cork, Ireland

${ }^{15}$ Bioclimatology Group, Büsgen Institute, Georg-August University of Göttingen, Göttingen, Germany

${ }^{16}$ Department of Forest Ecology, Mendel University Brno, Zemedělská 3, 60300 Brno, Czech Republic

${ }^{17}$ ETH Zurich, Institute of Agricultural Sciences, 8092 Zurich, Switzerland

${ }^{18}$ Forest Services of Autonomous Province of Bolzano, Bolzano, Italy

${ }^{19}$ Finnish Forest Research Institute, 01301 Vantaa, Finland

${ }^{20}$ DREAM, CEFE, CNRS, UMR5175, 1919 route de Mende, 34293 Montpellier Cedex 5, France

${ }^{21}$ A. N. Severtsov Institute of Ecology and Evolution, Russian Academy of Sciences, Moscow 119071, Russia

Received: 19 September 2013 - Accepted: 11 October 2013 - Published: 4 November 2013 Correspondence to: W. Yuan (yuanwpcn@126.com) and W. Dong (dongwj@bnu.edu.cn) Published by Copernicus Publications on behalf of the European Geosciences Union.
GMDD

$6,5475-5488,2013$

Remote sensing of

gross primary

production

W. Yuan et al.

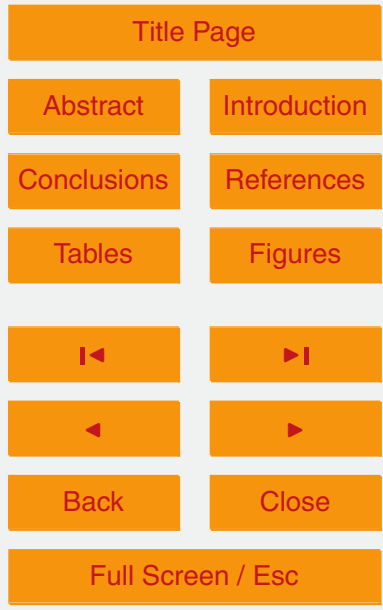

Printer-friendly Version

Interactive Discussion 


\section{Abstract}

Models of gross primary production (GPP) are currently parameterized with vegetationspecific parameter sets and therefore require accurate information on the distribution of vegetation to drive them. Can this parameterization scheme be replaced with 5 a vegetation-invariant set of parameter that can maintain or increase model applicability by reducing errors introduced from the uncertainty of land cover classification? Based on the measurements of ecosystem carbon fluxes from 150 globally distributed sites in a range of vegetation types, we examined the predictive capacity of seven light use efficiency (LUE) models. Two model experiments were conducted: (i) a constant set parameters for various vegetation types and (ii) vegetation-specific parameters. The results showed no significant differences in model performances to simulate GPP while using both sets of parameters. These results indicate that a universal set of parameters, which is independent of vegetation cover type and characteristics can be adopted in prevalent LUE models. Availability of this well tested and universal set of parameters 15 would help to improve the accuracy and applicability of LUE models in various biomes and geographic regions.

\section{Introduction}

In the past decades, a long series of terrestrial ecosystem models have been developed to simulate and predict the vegetation primary productivity, which play an important role in the global carbon cycle at various spatiotemporal scales (Cramer et al., 2001). However, modeling the carbon cycle using ecosystem models at continental to global scale is subject to large uncertainties, primarily due to uncertainties of model parameterizations (Knorr and Heimann, 2001). The conventional parameterization schemes assume a constant parameter sets for each vegetation types. Consequently, land cover products based on remote sensing technology are routinely used to characterize vegetation characteristics for model
Remote sensing of

gross primary

production

W. Yuan et al

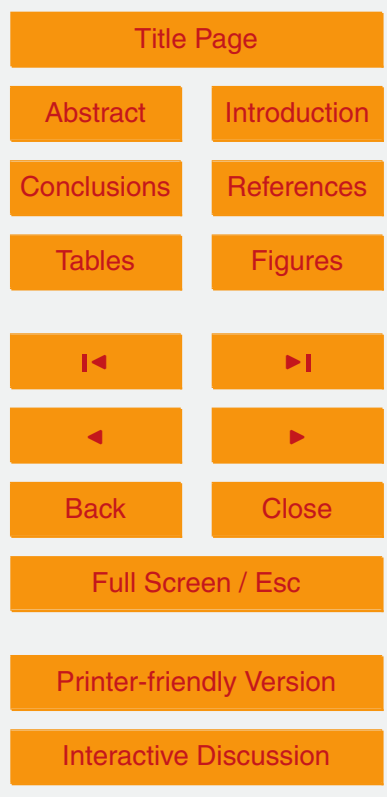

Interactive Discussion 
applications. However, classifying remote sensing images to obtain reliable and accurate land cover type and associated vegetation characteristics over large areas remains a major challenge because of the complexity of landscapes, availability and suitability of remote sensing data, uncertainty of image processing and classification 5 methods, etc. (Hansen et al., 2003).

Satellite-based light use efficiency (LUE) models have been widely used because they rely on simple algorithms to estimate gross primary production (GPP). Most LUE models are based on look-up tables to set the parameter values for given vegetation types (Running et al., 2004). Yet a few LUE models (CASA and EC-LUE) use a set 10 of constant parameters regardless of vegetation type by arguing that photosynthesis is independent of species and vegetation but driven by biophysical conditions such as mainly light, temperature and available water (Potter et al., 1993; Yuan et al., 2007, 2010). Moreover, Aber and Federer (1992) argued that the amount of carbon fixed through photosynthesis per light quantum intercepted is invariant of species. The use of invariant parameter values across vegetation types would clearly simplify the parameterization of LUE models at broad spatial scales and the prediction of GPP over large areas. However, the advantages of this approach have not yet been verified against surface observations. In this study, we tested a series of popular LUE models by using both vegetation invariant and vegetation dependent parameters across a range of geographic regions and ecosystem types. Model predictions of GPP are finally validated using in situ observations from flux towers belonging to the global Fluxnet network (Baldocchi et al., 2001).

\section{Data and methods}

The LUE models are in general built on two fundamental assumptions (Goetz and

Prince, 1999; Running et al., 2004): (1) ecosystem GPP is linearly related to absorbed photosynthetically active radiation (APAR) through LUE, where LUE is defined as the amount of carbon fixed per unit of APAR, and (2) potential LUE may be reduced below
GMDD

$6,5475-5488,2013$

Remote sensing of

gross primary

production

W. Yuan et al.

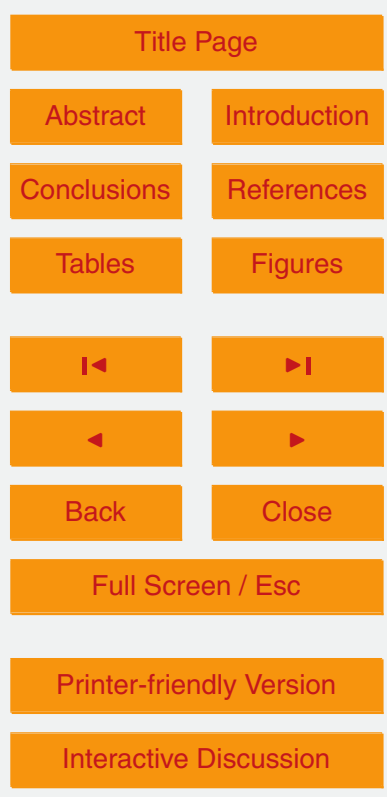


its theoretical potential value (i.e., realized LUE) by environmental stresses such as low temperature or water shortage (Landsberg and Sands, 2010). In this study, seven LUE models were selected to conduct a global comparison of model performance against GPP estimates from flux tower measurement: CASA (Potter et al., 1993), 5 CFix (Veroustraete et al., 2002), CFlux (Turner et al., 2006; King et al., 2011), ECLUE (Yuan et al., 2007, 2010), MODIS-GPP (Running et al., 2004), VPM (Xiao et al., 2004) and VPRM (Mahadevan et al., 2008). Detailed informations about these models are reported in the supplementary online material.

The LaThuile FLUXNET dataset was used in this study (http://www.fluxdata.org). 10 A total of 150 eddy covariance $(E C)$ towers from five major terrestrial biomes were analysed: deciduous broadleaf forest (DBF, 25 sites), evergreen broadleaf forest (EBF, 14 sites), evergreen needleleaf forest (ENF, 62 sites), grassland (GRA, 40 sites) and mixed forest (MF, 9 sites) (Table S1; Fig. S1). Detailed information on data processing and site information (i.e. vegetation, climate and soils) are available at the LaThuile 15 FLUXNET web portal (http://www.fluxdata.org). The methodology applied to derive GPP from the net ecosystem exchange is reported in Reichstein et al. (2005).

Two model experiments were conducted to evaluate the vegetation-invariant parameters in LUE models. First, we calibrated the seven LUE models each with a set of invariant model parameters that did not change across all vegetation types. Half of the sites were randomly selected to calibrate model parameters, and the remaining half were used for model validation. The nonlinear regression procedure (Proc NLIN) in the Statistical Analysis System (SAS, SAS Institute Inc., Cary, NC, USA) was used to optimize the model parameters. Second, model parameters were calibrated for each model and vegetation type. Same site selection criterion and calibration process were 25 applied within each vegetation type. Two metrics, the coefficient of determination $\left(R^{2}\right)$ and the root mean square error (RMSE), were used to evaluate the performance of the LUE models.

The 8 day MODIS-NDVI/EVI data (MOD13) and MODIS-fPAR/LAI (MOD15) with $1 \mathrm{~km}$ spatial resolution were the basis for model verification at the EC sites. Quality
GMDD

6, 5475-5488, 2013

Remote sensing of

gross primary

production

W. Yuan et al.

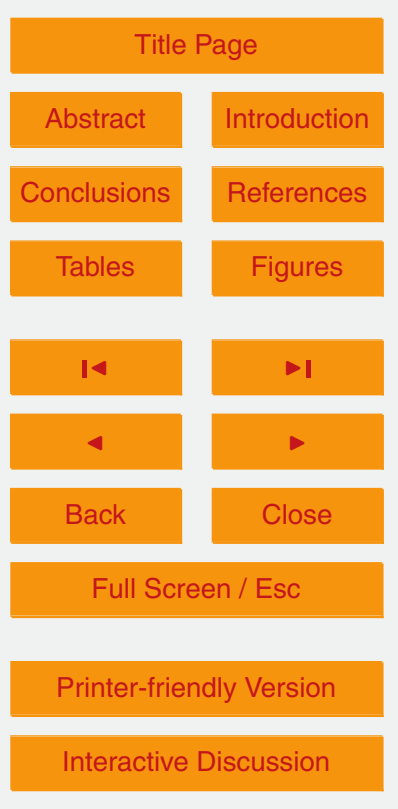

Interactive Discussion 
control (QC) flags, which signal cloud contamination in each pixel, were examined to screen and reject NDVI, EVI and fPAR data of insufficient quality. We temporally filled the missing or unreliable values at each $1 \mathrm{~km}$ MODIS pixel based on their corresponding quality assessment data fields as proposed by Zhao et al. (2005).

\section{$5 \quad 3$ Results and discussion}

Calibrated parameters of several models across most vegetation types did not show significant differences with those derived from individual vegetation types (Table 1). In the CASA model, potential LUE value $\left(\varepsilon_{0}\right)$ calibrated at all sites was $0.91 \pm 0.14 \mathrm{~g} \mathrm{Cm}^{-2} \mathrm{MJ}^{-1}$, which only significantly differed from the calibrated to values at grassland $\left(0.78 \pm 0.17 \mathrm{~g} \mathrm{C} \mathrm{m}^{-2} \mathrm{MJ}^{-1}\right)$. Similar results were found at the ECLUE and VPM models, the calibrated $\varepsilon_{0}$ value $\left(1.73 \pm 0.12 \mathrm{~g} \mathrm{Cm}^{-2} \mathrm{MJ}^{-1}\right.$ and $2.08 \pm$ $0.17 \mathrm{~g} \mathrm{Cm}^{-2} \mathrm{MJ}^{-1}$ ) for all sites did not show the significant differences with those of other vegetation types (Table 1). There were more than one parameter at other models, and the results showed complex relationships among parameters (Table 1).

15 For example, in the VPRM model, the calibrated $\varepsilon_{0}$ and $\mathrm{PAR}_{0}$ at all sites significantly differed from those of deciduous broadleaf forest, however, they showed larger and lower inversed parameter values over all sites, respectively (Table 1).

Among the seven LUE models there were no significant differences in model performance between the two different parameterization schemes according to mean 20 GPP, RMSE and coefficient of determination $\left(R^{2}\right)$ (Fig. 1). Especially, the slopes of regression lines between mean GPP estimations did not show significant differences, indicating that these two different parameterizations rarely changed the magnitude of GPP predictions (Fig. 1). These results indicate that the parameterization scheme of the LUE models can potentially be simplified using a set of constant vegetationindependent parameter values for each model, which will reduce the uncertainty generated from land cover misclassification, while simplifying their use.
GMDD

$6,5475-5488,2013$

Remote sensing of

gross primary

production

W. Yuan et al.

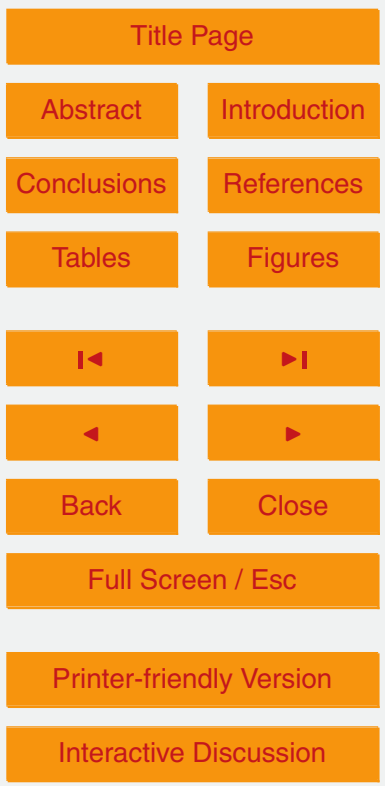


Our conclusion is supported by plant physiological evidences. Although different photosynthesis pathway can occur in different species, some features are always the same. Theoretically, plants can assimilate $1 \mathrm{~mol} \mathrm{CO}_{2}$ using $8 \mathrm{~mol}$ absorbed radiation (Hall and Rao, 1999). Another reason for the good performance of the vegetation5 invariant model parameters in the tested LUE models is the use of a satellitederived vegetation index, which holistically captures the overall state of structural and physiological vegetation characteristics (e.g. leaf area index, chlorophyll and nitrogen content).

Most LUE models assume the potential LUE to occur at optimal temperature and 10 have also been found to influence the photosynthetic potentials (Kergoat et al., 2008; Peltoniemi et al., 2012). Remotely sensed vegetation index, however, is highly related to leaf nitrogen content (Hansen and Schjoerring, 2003; Zhu et al., 2008; Yao et al., 2010; Li et al., 2010). A strong correlation exists between leaf chlorophyll and leaf nitrogen concentration (Ercoli et al., 1993), and the visible light reflectance is primarily determined by the chlorophyll of the leaf (Campbell, 2002; Alchanatis et al., 2005). Therefore, NDVI is an effective index for relative plant nitrogen status. Previous studies have shown that remotely sensed imagery can provide valuable information about infield nitrogen variability (Chang et al., 2003; Sripada et al., 2005).

Most current LUE models use look-up tables to define vegetation specific model parameters for regional and global applications. Therefore the availability of satellite derived land cover products is a prerequisite for model parameterization. For example, the MODIS land cover product (MOD-12) is used to run the MODIS-GPP product (Running et al., 2004). However, a previous study showed the accuracy of the MODIS land cover product is only about $75 \%$ (Friedl et al., 2010). If such products were used for estimating GPP, additional errors would be introduced from the uncertainty in land cover classification to the regional estimates of GPP.

Results from this study clearly show similar performance of the LUE models in predicting GPP using either the vegetation-dependent or invariant model parameters.

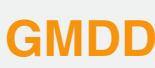

6, 5475-5488, 2013

Remote sensing of

gross primary

production

W. Yuan et al.

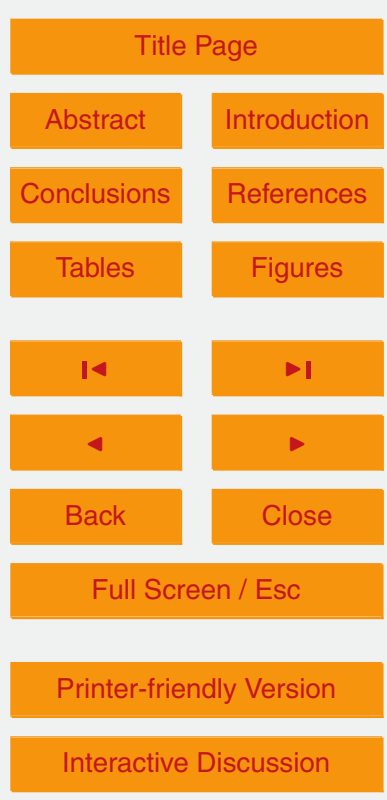

Interactive Discussion 
This result implies that such approach may significantly reduce the uncertainty of GPP estimates at regional to global scales. This will also increase the feasibility of quantifying and mapping GPP changes over time and land use change. This is particularly the case since acquiring frequent high-quality land cover change 5 information over large areas has been a major challenge (Hansen et al., 2003).

\section{Summary and conclusions}

Selecting adequate model parameter values is critical for estimating vegetation production within various process models. Considering the variability and uniqueness of various ecosystems in primary production, assigning a varying parameter set in 10 accordance with vegetation types has been a common parameterization strategy. However, this approach requires high-quality vegetation cover information. Current vegetation cover datasets over large areas contain large uncertainties that propagate into GPP simulations at regional and global scales. In this study, two model experiments were conducted to examine the differences in GPP predictions by seven 15 LUE models using alternatively vegetation variant and invariant parameters. No significant differences were found between the two parameterization schemes. These results indicate that the application of LUE models can potentially be simplified with a constant parameterization scheme that is independent of land cover types and associated vegetation characteristics.

\section{Supplementary material related to this article is available online at http://www.geosci-model-dev-discuss.net/6/5475/2013/ gmdd-6-5475-2013-supplement.pdf.}

GMDD

$6,5475-5488,2013$

Remote sensing of

gross primary

production

W. Yuan et al.

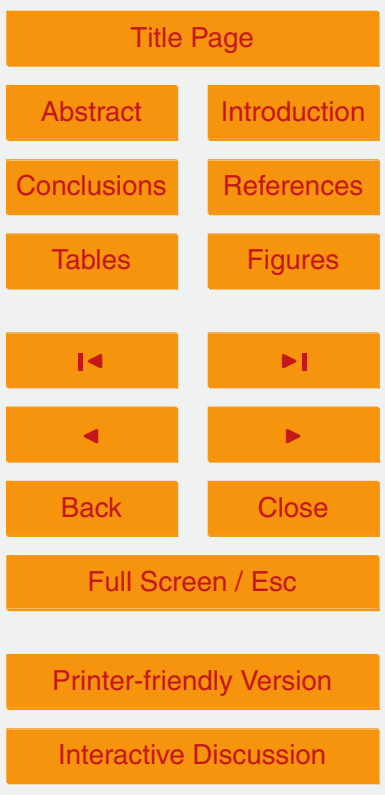


Acknowledgements. This study was supported by the National Natural Science Foundation of China (41201078), the National High Technology Research and Development Program of China (863 Program) (2013AA122003), Program for New Century Excellent Talents in University (NCET-12-0060), LCLUC Program of NASA and the Fundamental Research

5 Funds for the Central Universities. This work used eddy covariance data acquired by the FLUXNET community and in particular by the following networks: AmeriFlux (US Department of Energy, Biological and Environmental Research, Terrestrial Carbon Program (DE-FG0204ER63917 and DE-FG02-04ER63911)), AfriFlux, AsiaFlux, CarboAfrica, CarboEuropelP, Carboltaly, CarboMont, ChinaFlux, Fluxnet-Canada (supported by CFCAS, NSERC, BIOCAP,

10 Environment Canada, and NRCan), GreenGrass, KoFlux, LBA, NECC, OzFlux, TCOS-Siberia, and USCCC. We acknowledge the financial support to the eddy covariance data harmonization provided by GHG-Europe, FAO-GTOS-TCO, iLEAPS, Max Planck Institute for Biogeochemistry, National Science Foundation, University of Tuscia, Université Laval, Environment Canada and US Department of Energy and the database development and technical support from Berkeley

15 Water Center, Lawrence Berkeley National Laboratory, Microsoft Research eScience, Oak Ridge National Laboratory, University of California - Berkeley and the University of Virginia.

\section{References}

Aber, J. D. and Federer, C. A.: A generalized, lumped-parameter model of photosynthesis, evapotranspiration and net primary production in temperate and boreal forest ecosystems, Oecologia, 92, 463-474, 1992.

Alchanatis, V. Z., Schmilovitch, Z., and Meron, M.: In-field assessment of single leaf nitrogen status by spectral reflectance measurements, Prec. Agr., 6, 25-39, 2005.

Baldocchi, D., Falge, E., Gu, L., Olson, R., Hollinger, D., Running, S., Anthoni, P., Bernhofer, C., Davis, K., Evans, R., Fuentes, J., Goldstein, A., Katul, G., Law, B., Lee, X., Malhi, Y., Meyers, T., Munger, W., Oechel, W., Paw, K. T., Pilegaard, K., Schmid, H. P., Valentini, R., Verma, S., Vesala, T., Wilson, K., and Wofsy, S.: FLUXNET: a new tool to study the temporal and spatial variability of ecosystem - carbon dioxide, water vapor, and energy flux densities, B. Am. Meteorol. Soc., 82, 2415-2434, 2001.

Campbell, J. B.: Introduction to Remote Sensing, New York, the Guilford Press, New York, USA, 2002.

GMDD

6, 5475-5488, 2013

Remote sensing of

gross primary

production

W. Yuan et al.

Title Page

Abstract

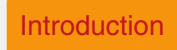

Conclusions

References

Tables

Figures

14

$\rightarrow 1$

4

Back

Close

Full Screen / Esc

Printer-friendly Version

Interactive Discussion

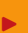

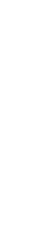


Chang, J., Clay, D. E., Dalsted, K., Clay, S., and O'Neill, M.: Corn yield prediction using multispectral and multidate reflectance, Agron. J., 95, 1447-1453, 2003.

Cramer, W., Bondeau, A., Woodward, F. I., Prentice, I. C., Betts, R. A., Brovkin, V., Cox, P. M., Fisher, V., Foley, J. A., Friend, A. D., Kucharik, C., Lomas, M. R., Ramankutty, N., Sitch, S.,

5 Smith, B., White, A., and Young-Molling, C.: Global response of terrestrial ecosystem structure and function to $\mathrm{CO}_{2}$ and climate change: results from six dynamic global vegetation models, Glob. Change Biol., 7, 357-373, 2001.

Ercoli, L., Mariotti, M., Masom, A., and Massantini, F.: Relationship between nitrogen and chlorophyll content and spatial properties in maize leaves, Eur. J. Agron., 2, 113-117, 1993.

10 Friedl, M. A., Sulla-Menashe, D., Tan, B., Schneider, A., Ramankutty, N., Sibley, A., and Huang, X.: MODIS Collection 5 global land cover: algorithm refinements and characterization of new datasets, Remote Sens. Environ., 114, 168-182, 2010.

Goetz, S. and Prince, S.: Modelling terrestrial carbon exchange and storage: evidence and implications of functional convergence in light-use efficiency, Adv. Ecol. Res., 28, 57-92, 151999.

Hall, D. O. and Rao, K.: Photosynthesis, Cambridge University Press, Cambridge, 1999.

Hansen, M. C., DeFries, R. S., Townshend, J., Carroll, M., Dimiceli, C., and Sohlberg, R.: Global percent tree cover at a spatial resolution of 500 meters: first results of the MODIS Vegetation Continuous Fields algorithm, Earth Interact., 7, 1-15, 2003.

20 Hansen, P. M. and Schjoerring, J. K.: Reflectance measurement of canopy biomass and nitrogen status in wheat crops using normalized difference vegetation indices and partial least squares regression, Remote Sens. Environ., 86, 542-553, 2003.

Kergoat, L., Lafont, S., Arneth, A., Dantec, V. A., and Saugier, B.: Nitrogen controls plant canopy light-use efficiency in temperate and boreal ecosystems, J. Geophys. Res., 113, G04017, doi:10.1029/2007JG000676, 2008.

King, D. A., Turner, D. P., and Ritts, W. D.: Parameterization of a diagnostic carbon cycle model for continental scale application, Remote Sens. Environ., 115, 1653-1664, 2011.

Knorr, W. and Heimann, M.: Uncertainties in global terrestrial biosphere modeling: 1. A comprehensive sensitivity analysis with a new photosynthesis and energy balance 30 scheme, Global Biogeochem. Cy., 15, 207-225, 2001.

Landsberg, J. J. and Sands, P.: Physiological ecology of forest production: principles, processes and models, Academic Press, London, 4, 165-178, 2010.

Remote sensing of

gross primary

production

W. Yuan et al.

Title Page

Abstract

Conclusions

Tables

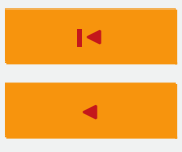

Back

Full Screen / Esc

Printer-friendly Version

Interactive Discussion 
Li, F., Miao, Y. X., Hennig, S. D., Gnyp, M. L., Chen, X., Jia, L., and Bareth, G.: Evaluating hyperspectral vegetation indices for estimating nitrogen concentration of winter wheat at different growth stages, Precis. Agric., 11, 335-357, 2010.

Mahadevan, P., Wofsy, S. C., Matross, D. M., Xiao, X., Dunn, A. L., Lin, J. C., Gerbig, C., Munger, J. W., Chow, V. Y., and Gottlieb, E. W.: A satellite-based biosphere parameterization for net ecosystem $\mathrm{CO}_{2}$ exchange: Vegetation Photosynthesis and Respiration Model (VPRM), Global Biogeochem. Cy., 22, 1-17, 2008.

Peltoniemi, M., Pulkkinen, M., Kolari, P., Duursma, R. A., Montagnani, L., Wharton, S., Lagergren, F., Takagi, K., Verbeeck, H., Christensen, T., Vesala, T., Falk, M., Loustau, D., and Mäkelä, A.: Does canopy mean nitrogen concentration explain variation in canopy light use efficiency across 14 contrasting forest sites?, Tree Physiol., 32, 200-218, 2012.

Potter, C. S., Randerson, J. T., Field, C. B., Matson, P. A., Vitousek, P. M., Mooney, H. A., and Klooster, S. A.: Terrestrial ecosystem production: a process model based on global satellite and surface data, Global Biogeochem. Cy., 7, 811-841, 1993.

15 Reichstein, M., Falge, E., Baldocchi, D., Papale, D., Aubinet, M., Berbigier, P., Bernhofer, C., Buchmann, N., Gilmanov, T., Granier, A., Grünwald, T., Havrankova, K., Ilvesniemi, H., Janous, D., Knohl, A., Laurila, T., Lohila, A., Loustau, D., Matteucci, G., Meyers, T., Miglietta, F., Ourcival, J. M., Pumpanen, J., Rambal, S., Rotenberg, E., Sanz, M., Tenhunen, J., Seufert, G., Vaccari, F., Vesala, T., Yakir, D., and Valentini, R.: On the separation of net ecosystem exchange into assimilation and ecosystem respiration: review and improved algorithm, Glob. Change Biol., 11, 1424-1439, 2005.

Running, S. W., Nemani, R. R., Heinsch, F. A., Zhao, M., Reeves, M., and Hashimoto, H.: A continuous satellite-derived measure of global terrestrial primary production, Bioscience, 54, 547-560, 2004.

Sripada, R. P., Heiniger, R. W., White, J. G., and Weisz, R.: Aerial color infrared photography for determining late-season nitrogen requirements in corn, Agron. J., 97, 1443-1451, 2005.

Turner, D. P., Ritts, W. D., Styles, J. M., Yang, Z., Cohen, W. B., Law, B. E., and Thornton, P. E.: A diagnostic carbon flux model to monitor the effects of disturbance and interannual variation in climate on regional NEP, Tellus B, 58, 476-490, 2006.

30 Veroustraete, F., Sabbe, H., and Eerens, H.: Estimation of carbon mass fluxes over Europe using the C-Fix model and Euroflux data, Remote Sens. Environ., 83, 376-399, 2002. 
Xiao, X. M., Zhang, Q. Y., Braswell, B., Urbanski, S., Boles, S., Wofsy, S., Moore III, B., and Ojima, D.: Modeling gross primary production of temperate deciduous broadleaf forest using satellite images and climate data, Remote Sens. Environ., 91, 256-270, 2004.

Yao, X., Zhu, Y., Tian, Y. C., Feng, W., and Cao, W. X.: Exploring hyperspectral bands and 5 estimation indices for leaf nitrogen accumulation in wheat, Int. J. Appl. Earth Obs., 12, 89100, 2010.

Yuan, W. P., Liu, S. G., Zhou, G. S., Zhou, G. Y., Tieszen, L. L., Baldocchi, D., Bernhofer, C., Gholz, H., Goldstein, A. H., Goulden, M. L., Hollinger, D. Y., Hu, Y., Law, B. E., Stoy, P. C., Vesal, T., Wofsy, S. C., and other AmeriFlux collaborators: deriving a light use efficiency model from eddy covariance flux data for predicting daily gross primary production across biomes, Agr. Forest Meteorol., 143, 189-207, 2007.

Yuan, W. P., Liu, S. G., Yu, G. R., Bonnefond, J., Chen, J., Davis, K., Desai, A. R., Goldstein, A. H., Gianelle, D., Rossi, F., Suyker, A. E., and Verma, S. B.: Global estimates of evapotranspiration and gross primary production based on MODIS and global meteorology data, Remote Sens. Environ., 114, 1416-1431, 2010.

Zhao, M., Heinsch, F. A., Nemani, R., and Running, S. W.: Improvements of the MODIS terrestrial gross and net primary production global data set, Remote Sens. Environ., 95, 164-176, 2005.

Zhu, Y., Yao, X., Tian, Y. C., Liu, X. J., and Cao, W. X.: Analysis of common canopy vegetation indices for indicating leaf nitrogen accumulations in wheat and rice, Int. J. Appl. Earth Obs., 10, 1-10, 2008.

Remote sensing of

gross primary

production

W. Yuan et al.

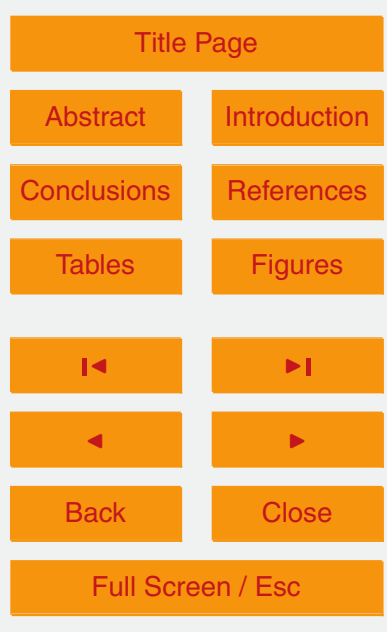

Printer-friendly Version

Interactive Discussion 
Table 1. Calibrated model parameter values for seven LUE models and two parameterization schemes.

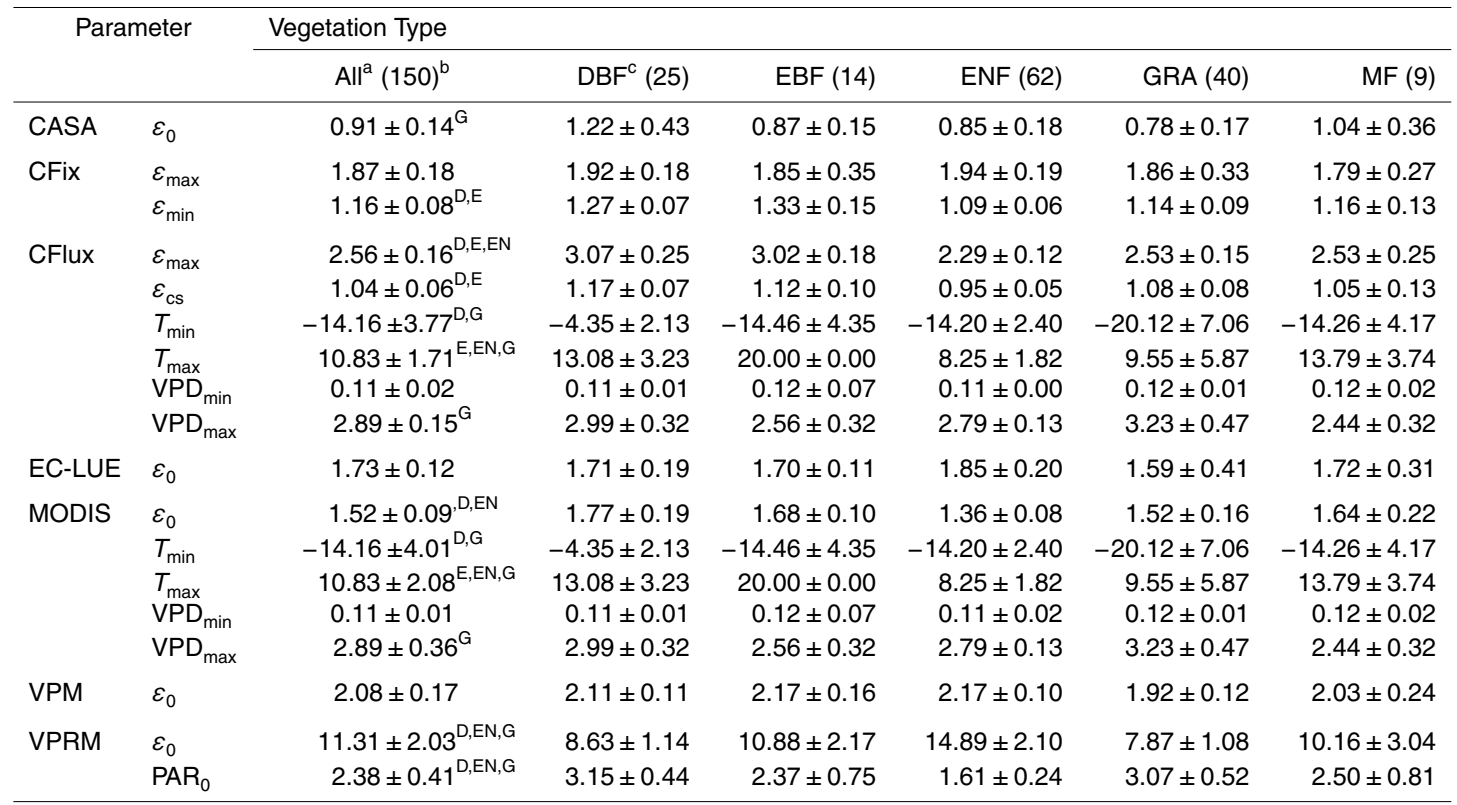

${ }^{a}$ All: parameter values calibrated through all sites, and detailed information about these parameters are reported in the supplementary online material.

${ }^{\mathrm{b}}$ The numbers indicate the site number of each vegetation type.

${ }^{\mathrm{C}}$ DBF, EBF, ENF, GRA, MF: calibrated parameter values within deciduous broadleaf forest, evergreen broadleaf forest, evergreen needleleaf forest, grassland, mixed forest respectively. The capital letters, showed at the column "All", indicate the significant differences with parameters calibrated within vegetation types (D, E, EN, G, M represent DBF, EBF, ENF, GRA, MF). The lowercase letters at the other columns indicate significant differences among several of vegetation types. Parameters information is provided in the Supplement. The unit of parameters: $\mathrm{gC} \mathrm{m}^{-2} \mathrm{MJ}^{-1}$ APAR for $\varepsilon_{0 / \mathrm{max} / \mathrm{min} / \mathrm{cs} /} ; \mathrm{kPa}$ for VPD $\mathrm{min} / \mathrm{max} ;{ }^{\circ}$ for $T_{\min / \mathrm{max}}$; $\mathrm{MJ} \mathrm{m}^{-2}$ for PAR .

\section{GMDD}

$6,5475-5488,2013$

Remote sensing of

gross primary

production

W. Yuan et al.

\section{Title Page}

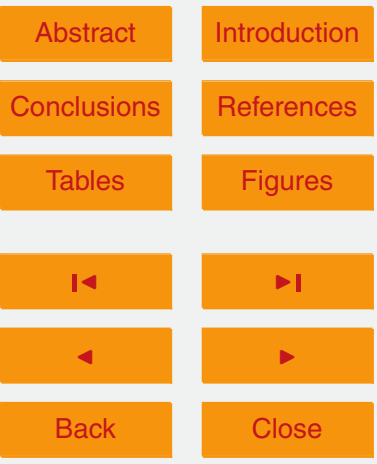

Full Screen / Esc

Printer-friendly Version

Interactive Discussion 

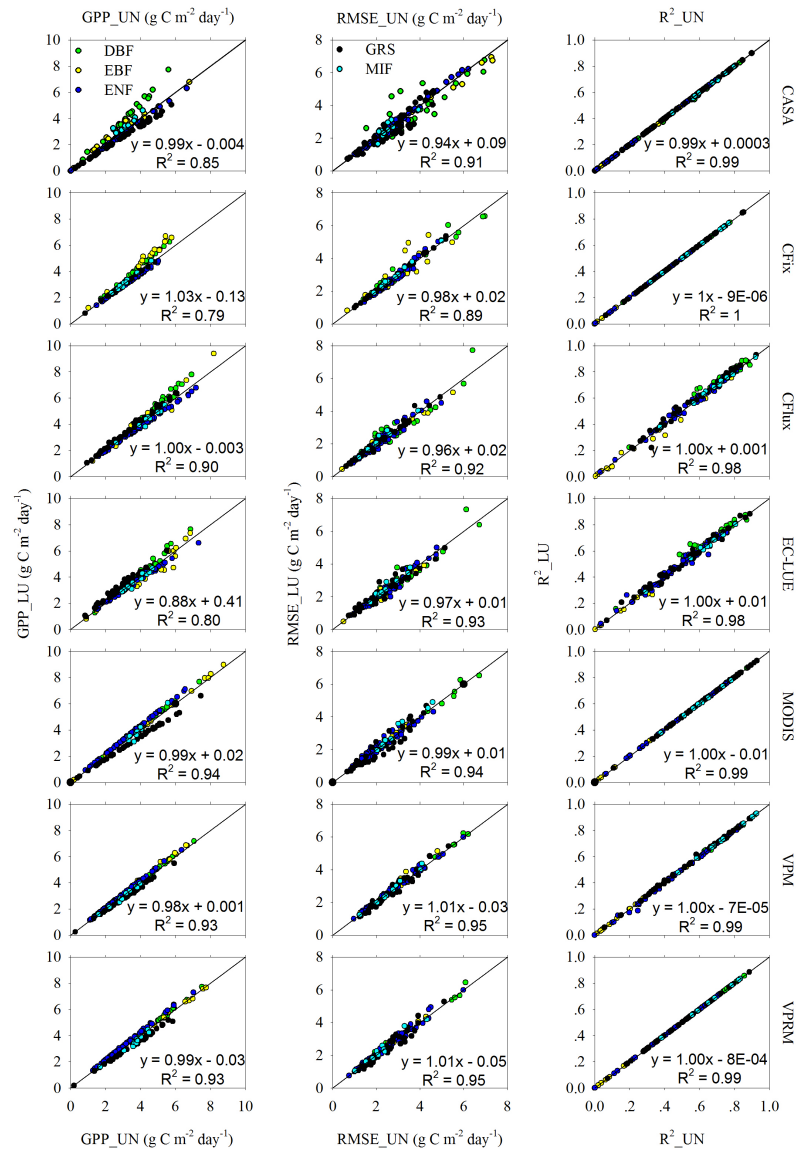

\section{GMDD}

$6,5475-5488,2013$

Remote sensing of

gross primary

production

W. Yuan et al.

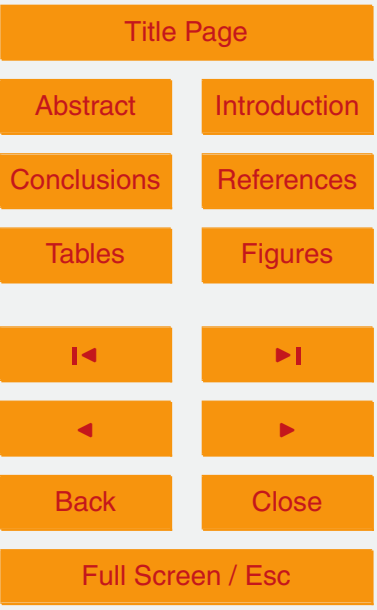

Printer-friendly Version

Fig. 1. Model comparison of the two model parameterization schemes. LU indicate the parameterization using look-up tables while UN indicate that model use a vegetation-invariant parameter set. 